\title{
The Information-Seeking Habits of Baptist Ministers
}

Joshua D. Lambert

Missouri State University

Follow this and additional works at: https://bearworks.missouristate.edu/articles-lib

\section{Recommended Citation}

Lambert, Joshua D. "The information-seeking habits of Baptist ministers." Journal of Religious \& Theological Information 9, no. 1-2 (2010): 1-19.

This article or document was made available through BearWorks, the institutional repository of Missouri State University. The work contained in it may be protected by copyright and require permission of the copyright holder for reuse or redistribution.

For more information, please contact BearWorks@library.missouristate.edu. 
The Information-seeking Habits of Baptist Ministers

Joshua D. Lambert

Missouri State University

Joshua D. Lambert, Missouri State University Libraries, Missouri State University.

Correspondence concerning this article should be addressed to Joshua Lambert, Duane G. Meyer

Library, Missouri State University, Springfield, MO 65897.

Email: jlambert@missouristate.edu 


\begin{abstract}
Objective - The aim of this paper is to determine how Baptist ministers seek information. Further research questions were used to narrow down the broad aim to a workable level. What causes ministers to seek and stop seeking information? What sources do they use? How do the information-seeking habits change as they pursue their various roles?
\end{abstract}

Methods - A multiple-case study design was used. Ten ministers were interviewed with a protocol that used the Critical Incident Technique. Interviews were transcribed and coded in order to identify patterns.

Results - Baptist ministers sought information in order to accomplish a wide variety of administrative tasks, prepare for sermons, and provide counsel. When ministers searched for information in the role of administrators, they preferred informal sources of information but often used formal sources also. When searching as preachers, they used formal sources. Level of effort was influenced by experience, potential impact, and the importance of the task. When they had enough information to complete a task and when collecting more information was not worth the effort, ministers stopped looking for information.

Conclusions - Baptist ministers varied their information-seeking process based upon the roles they played, primarily the roles of administrator and preacher. 


\section{The Information-seeking and Information-stopping Behavior of Baptist Ministers}

Religious ministers command a huge audience in the United States. According to a recent study, $56 \%$ of the general public said they attended church in the past month (Barna Group). Evangelical Christian ministers have a strong tradition of communicating information from the Bible to their congregation by preaching up to three times per week and performing administrative duties to help keep their churches running smoothly. This requires the minister to locate information and use it effectively. This study endeavors to describe the informationseeking habits of a specific set of ministers and relate those results to other information-seeking studies.

This study describes the information-seeking habits of Southern Baptist ministers with an emphasis on their administrative role. Phillips' research of "the relationship between work roles and information-seeking behaviors" of Protestant ministers suggested that further research be done relating the two (137). This endeavor furthers that understanding. In addition to roles, this study pays special attention to the stopping behavior of ministers. Stopping behavior occurs when the minister quits looking for information. This study is the first to investigate that aspect of minister information-seeking. The research questions and protocol of this study are taken in large part from Lisl Zach's article, "When is 'Enough' Enough," but the user group has been changed from arts administrators to Baptist ministers.

\section{Literature Review}

According to Dervin, needs arise in specific situations and create gaps in a person's knowledge that he or she must fill in order to satisfy those needs (Dervin and Dewdney 507). Thanks to Dervin's foundation, information studies in the past twenty years have tended to focus 
on how certain populations look for and use information (Wicks 205). This is in contrast with the idea that information holds its own value and meaning apart from the information seeker and apart from a specific situation. In other words, the information seeker's perception of whether a need is met is as important as, or more important than, the specific information being delivered. This current study continues the trend of examining a specific user group to determine how they look for and use information.

Zach's study developed a model of information-seeking as it applied to her user group, arts administrators ("When is "Enough" Enough?" 28). Her model drew from the stages Kuhlthau (Kuhlthau) developed to describe the information search process. There was a gap in the research, according to Zach, when it came to exploring the stopping rules during the information-seeking process ("When is "Enough" Enough?" 25). For this reason, an emphasis in her study was to explore the stopping behavior of arts administrators. In addition, she narrowed the inquiry down to administrative information-seeking tasks. She found that "arts administrators do not consider information-seeking to be a discrete managerial task", they used experience to fill information needs, and "they are 'satisficers' when it comes to seeking information" (Zach, "When is "Enough" Enough?" 32). This present study adapts Zach's framework and protocol in order to study information-seeking and stopping behavior of Baptist ministers.

There is a sizable body of Library and Information Science (LIS) literature related to ministers, theology students (many of whom will become ministers), and theological educators. Wicks divided this body of literature into four categories (207). While all of the categories below may influence this study, the fourth one is the most relevant. 
- $\quad$ Background material found in the general literature on the religious scene in the country."

- References to ministers in LIS studies that are not primarily about ministers.

- Research on "specific aspects of clergy and information exchange." This includes how much ministers use libraries, how they use computers, and research about their reading habits.

- $\quad$ "Four doctoral theses which may be considered major studies of clergy and their information-seeking behavior."

The four doctoral theses in the last category mentioned by Wicks include Porcella, Allen, Phillips, and Tanner. Porcella used both surveys and interviews to collect information. He found that doctrinal viewpoint affected the patterns of ministerial information-seeking, though results varied depending on type of information source (Porcella 98). Conservative ministers did not read as heavily about social issues and did not use institutional libraries as often, but they read more heavily "in the Bible and in books directly related to the Bible" (Porcella 98). Allen found that information use of Baptist leaders in Central America was generally the same as the use found in the United States (231). Allen found that the primary source for theological information was mass media in the form of books, that those who held more leadership positions read and used libraries more, and that local church ministers were a "prime informal interpersonal resource" (207). Tanner found that ministers were very utilitarian in that they gathered information for a specific need while at the same time they looked for information to use in the future (317). Many of the information needs were the result of church member questions that the minister would try to answer. Tanner even called ministers "information professionals" due to 
their role of providing information to people (21). Phillips provided a basis for studying minister roles, hypothesized that different roles invoke different information-gathering habits, and found that to be the case $(27,3,126)$. Wicks considered the ideas of the "pastor's role" and the "pastor's world" and found that the information-seeking behavior of pastoral clergy was sometimes influenced by their work roles and work worlds (222). A review of the literature related to minister roles is below.

Since Wicks' article in 1999, there has been one more thesis published and three articles that directly relate to the information-seeking habits of ministers (Roland, "Interpreting Scripture"; Roland, "Clergy Sense-making”; K. L. Smith and V. L. Smith). Roland, using Dervin's sense-making framework, "sought to discover the information-seeking and use behavior of a clergy member as he goes about the weekly task of interpreting Scripture in preparation of a sermon"(“Clergy Sense-making” 11). Roland articulated the role of the Holy Spirit in the information-seeking habits of his subject. He said, "The informant verbs his world, especially the sermon preparation process, in such a way that combines connectivities both anchored in the real and which soar beyond the real by faith" ("Clergy Sense-making” 29). Smith and Smith used a survey to measure Internet use of ministers. The study fits into Wicks' third category of LIS literature about ministers. They found that $88 \%$ of ministers owned computers and used the Internet (K. L. Smith and V. L. Smith 14). The most cited purpose for Internet use was denominational use such as news, directory information, and discussion lists (K. L. Smith and V. L. Smith 15). About half of the ministers also used the Internet in some way to prepare sermons. Michels, when researching how sermon preparation using the Internet compared to not using the Internet, found that his respondent "did not describe an experience with the Internet that has 
significantly transformed intentional activities surrounding preparation for worship" (175). He considered the Internet to be another source, along with the traditional print sources, from which to seek information. Further, Michels describes an "ongoing dialogue" that occurred between a minister and his congregation, and posits that such online dialogue may increase congregational engagement in the sermon development process (175).

Ministers take on different roles to perform the variety of duties required of them. Sarbin and Allen define "role" as "conduct related to one's position rather than to one's self" (488). Blizzard specified six roles that ministers take on: preacher, pastor, priest, teacher, organizer, and administrator (84). Phillips researched the information-seeking habits of ministers as they related to the roles of preacher and administrator. He found that there was a difference in "choice of information channel and in the methods used to retrieve information" as well as other information-seeking behaviors (Phillips 125). Formal information channels are "channels organized or produced as an information channel" (Phillips 126). Ministers preferred formal channels and impersonal sources when they preached, and informal channels and personal sources when they did administrative tasks. The formal information sources were often part of the minister's personal library. Porcella and Tanner did not directly study minister informationseeking habits as they pertain to role, but they did refer to different roles that ministers take. Wicks used the above studies to identify and use the three roles of preaching, caregiving, and administration (208). He found that "formal sources were preferred when preparing to preach and informal when performing non-ceremonial caregiving duties as well as when making administrative decisions" (Wicks 222). While Roland cited the previous studies about roles, he examined only the role of preacher (“Clergy Sense-making”). Smith and Smith agreed with 
Wicks and Phillips that ministers consulted a variety of information sources for sermon preparation but consulted denominational sources when they made administrative decisions.

\begin{abstract}
Aims
As adapted from Zach, the research problem in this study is as follows: What is the nature of the information-seeking process used by Baptist ministers ("When is "Enough" Enough?" 25)? The research questions below address the problem by listing more specific aspects of information-seeking and making it easier to develop a protocol. The first four research questions are adapted from Zach. The fifth continues research done by Phillips, Tanner, and Wicks which relates changes in information-seeking to changes in minister role.
\end{abstract}

- What causes ministers to seek information?

- What sources do they use in acquiring that information?

- What other factors (if any) contribute to the level of effort invested in seeking information?

- What factors (stopping criteria) influence ministers to determine that they have "enough" information to end the information-seeking process?

- How do the information-seeking habits of ministers change as they pursue their various roles?

\title{
Methods
}

In order to capture ministers' thoughts and ideas about their information-seeking behavior, I chose to use a multiple-case study design. I contacted the ministers and considered each interview to be one case. The multiple cases combined to make a multiple-case study (Yin). Information-seeking behavior has a great deal to do with motivations, feelings, and convictions, 
and such things are difficult or impossible to experiment on or observe. For this reason, personal interviews were the chosen method for collecting information.

In order to maintain consistency among the sample, I set the following criteria. All of the ministers in this study served in Southern Baptist churches that were part of the same regional association in the Midwestern United States. I chose to limit the interviewees to this one association to make the sample more readily accessible. I included only full-time senior ministers who preached weekly. This ruled out music ministers, ministers of education, and other such minister titles. Due to job duty specialization in larger congregations, I included only churches with weekly Sunday morning attendance of less than 1000. Out of 76 churches in the association, 32 met the above criteria, but one of those did not have a minister. I interviewed ten out of the 31 ministers. The interviews took place during 2008 and 2009.

Experience and education levels varied among the ministers. Each minister has a letter designation in the table below. Six ministers (B, D, G, H, I, J) in this study had a master's degree from a seminary, while minister $\mathrm{F}$ had a doctorate, and minister $\mathrm{C}$ was currently taking classes and working toward a master's degree. The other two ministers (A, E) had bachelor's degrees in Christian ministry with many years of experience. Years of service as full-time preaching ministers varied from one year to over thirty. The minister with one year of service had worked full-time in his church previously but did not preach regularly, while the minister with more than 30 years of experience had actually retired once and decided to come back and work full-time again. All of the ministers were male.

Initially, I sent an email to each minister to solicit volunteers for the study. When that returned only two affirmative answers, I started at the top of an alphabetical list and called each 
of the churches to make contact. I interviewed the ministers based on the order of their availability. After the interviews, I transcribed them and coded them using a custom TiddlyWiki application. I made a second round of calls to find some ministers in the office who were not there initially. Partway through the second round of calls and after ten interviews, I met information saturation. Therefore interviews stopped. The multiple-case study design does not require a specific sample size or percentage. Rather, when further research produces no new findings, it means information saturation is met and that information gathering can stop (Zach, "Using a Multiple-Case Studies Design" 9).

The interview protocol for this study (found in Appendix A) came from Zach's study of arts administrators and was adapted to ministers ("When is "Enough" Enough?" 34). Using the Critical Incident Technique, I prompted the ministers to give an account of a recent instance when they had to search for information. The questions helped the ministers provide information relevant to research questions 1-4. Ministers each explained one critical incident in protocol questions 1-14. Questions 15-25 were more general and could apply to any information gathering. Without prompting from the interviewer, ministers answered the latter questions with sermon preparation as an emphasis, although they discussed other information gathering activities as well. While Zach's protocol asks arts administrators to "focus on the business side of the task, not the artistic one," the protocol used with the ministers asks them to "focus on the administrative side of the task." Using this wording required ministers to differentiate their roles of preacher and administrator. The following table lists each critical incident, the associated minister, the role the minister played during that incident, and a short description of the incident. The incidents have an alphanumeric designation between I-1 and I-23, while the unique 
designation for ministers is a letter between $\mathrm{A}$ and $\mathrm{J}$.

Table I. Critical Incidents and the Minister's Role

\{Table I is on the last page of this file as requested on the instructions for authors Webpage.

\section{Results}

In the following paragraphs, I consider the five questions listed in the Aims section above. The first four questions have their own section while I address the fifth question not by itself, but together with each of the four questions.

\section{What Causes Ministers to Seek Information?}

Ministers carry out a wide variety of tasks including preaching, presiding over weddings, hiring church staff, ministering to the sick, coordinating building projects, marriage counseling, and giving funerals. Each of these tasks may require the minister to search for information. I asked ministers, "What are the most common types of tasks for which you look for information?" The answers provided for this question and other comments throughout the interviews address the issue of what causes ministers to seek information.

The ministers mentioned specific tasks that I categorized into the three roles of preacher, caregiver, and administrator as Wicks did in his study (208). Of these roles, ministers cited preaching and administration many more times than caregiving. In fact, while they mentioned caregiving a few times during the interviews, there was not a single critical incident of caregiving explained during the interviews. The role of administrator includes tasks such as staff management, coordinating contract cleaning, building maintenance, and others described as I-1 
through I-17. The first part of the interview protocol specifically asks ministers to concentrate on the administrative side of a task, and therefore this study collected more information about the role of administrator than either preacher or caregiver. As mentioned above, the role of preacher includes formal teaching times such as those mentioned in incidents I-18 through I-23 but may also include informal teaching times such as "Bible study" or "Sunday School." The ministers did not describe such informal teaching times in enough detail for me to call them critical incidents for this study, but ministers referred to them during interviews. Examples of caregiving include marriage counseling, visiting the sick, and comforting the bereaved.

As an answer to protocol question 21, all ten ministers mentioned administration as a task for which they commonly search for information. Some examples and how many times ministers mentioned them are as follows: managing staff (3), building construction planning (3), church activity coordination (3), and contract cleaning (2). The critical incidents mentioned above are examples of administrative tasks, but ministers may not consider them "common." Minister F's words exemplify the others when it comes to common reasons to search for information:

I spend a pretty good deal of every week doing background research on passages . . . time wise that would be the area that I do the most research in. The second would be the ministries of our church. Finding new ways to do things that we are already doing or starting new ministries ... that we feel like we need to be doing.

All ten ministers mentioned preaching as a task for which they commonly search for information. Of the nine ministers who directly answered the question about common tasks, preaching/teaching was mentioned first or mentioned as the most time-consuming task for which they looked for information. While preparing sermons is the primary information-seeking task in 
the category of preaching, three ministers also mentioned preparing to give Bible studies. Minister B elaborated a wider view of information-seeking that others also mentioned, "without a doubt a majority of my information-seeking is related to messages ... it is study, it is research, it is prayer, it is a combination of everything I do to get ready for that."

To the surprise of the author, only ministers B and D mentioned caregiving as a common task for which they needed to seek information. Minister B ranked "counseling" above administrative tasks in time consumption. The other just mentioned it in passing. See the discussion section of this article for more information.

There were a few tasks which did not fit the above categories but were mentioned enough to note here. Three ministers (D, E, J) mentioned citing demographic information while preaching, and they used such information to make administrative decisions. Marriage and raising children are topics ministers address generally in preaching and specifically in family counseling situations.

\section{What Sources do Ministers Use in Acquiring Information?}

Ministers use a variety of information sources, but those interviewed mentioned the formal information channels of paper sources, the Internet, and software more than they mentioned informal channels such as personal contacts. The Bible and Biblical study aids informed much of the ministers' information-seeking, and ministers dedicated a large portion of each week to using those sources. However, the role the ministers filled greatly influenced what sources they used for information. 
The ministers mentioned sermon information sources 31 times, and of those, 28 sources were formal information channels. Formal information channels included Bibles, Bible commentaries, Bible concordances, Bible dictionaries, and published sermon collections. Only three sources came from informal information channels, and two of those were prayer as a source of information. The third informal channel was expert members in a congregation that a minister consulted to verify illustration veracity. When specifically asked if they used a library, all of the ministers said they did not.

In the role of administrator, ministers mentioned the informal channel of personal contacts more than any other source, though they used formal channels as well. They most often consulted ministers in other churches, then committee members working on a specific task, and then others in the congregation at large. The personal contacts were usually people the ministers had met and had known on a personal or professional level. When directly asked, all ministers said they prayed during the information-seeking process. One minister summed up the attitude expressed by the others: "We pray over everything."

Ministers spoke about the Internet as an information source more so than any other single source. Every minister said the Internet was a source for both administrative tasks and sermon preparation. They frequently mentioned helpful online Bible study tools and sermon illustration sites, which are functionally similar to book resources. The mentioned current awareness websites, including mainstream news outlets, blogs, and streaming radio broadcasts as sources that help them stay up-to-date. While Internet use was universal, most ministers also agreed that "there is just so much out there that it is hard to find what is actually valid and useful." 
When asked why they used the sources, the ministers gave many reasons. I have listed the top five reasons below, followed by the number of times ministers mentioned them. When referring to a person who was a source of information when looking for new furniture, minister A said the person could be "trusted to pay attention to things." Familiarity was often based on past experience or a recommendation from someone trustworthy who did have experience.

- confidence - 13

- familiarity - 11

- $\quad$ ease of use - 7

- relevance - 7

- timeliness - 7

\section{What Other Factors Contribute to the Level of Effort Invested in Seeking Information?}

There are wide varieties of factors that influenced the effort ministers put into seeking information. The effort factor most often cited by ministers was experience. They regularly mentioned that they gave two or three sermons or teaching lessons each week and that they were very comfortable preparing and presenting. Minister I, who had already retired once but began working full-time again said, "I have been doing this for so long I have it down pat." On the other end of the spectrum was minister $\mathrm{C}$, the youngest and most inexperienced person who had been a senior minister for a short period of time:

I've been an associate pastor for years and a lot of the responsibilities that come with that ... they are almost second nature at this point. I need new information but not to the extent that I am developing new skills. Versus being the senior pastor, so recently a lot of 
the administrative side, a lot of the management side, those things are very new to me ... so my information gathering on those is a lot more extensive because they are new tasks. Zach splits her factors into organizational and personal categories, but the distinction blurs for ministers due to their strong theological convictions that inform both organization and person ("When is "Enough" Enough?" 31). The following list contains the factors that influence level of effort when seeking information, followed by the number of times ministers mentioned the factor:

- Experience - 12

- Importance - 10

- $\quad$ Potential Impact - 9

- $\quad$ Timeliness - 6

- Accessibility of Information - 5

- Personal Satisfaction - 5

Importance influences the level of effort nearly as much as experience. Weekly preaching and teaching is a vital aspect of the ministers' tasks. Ministers also cited marriage counseling, bereavement, and "reaching lost people" as important situations that affect level of effort. For further discussion of what makes something important to ministers, see the discussion below.

Other factors that ministers mentioned include potential impact, timeliness, accessibility of information, and personal satisfaction. Considering that Southern Baptists are evangelicals and a primary goal is to spread their faith, it is not surprising that they expend more effort when they can impact more people. While the effort given to an event may not be high one month away from the event, the effort given the few days before may be quite high. Accessibility of 
information affects the level of effort, and that is one reason ministers often have large personal libraries. Personal libraries allow ministers quick access to the information they need the most. In addition, personal satisfaction helps determine level of effort. Minister A emphasized the extra time he takes to prepare for preaching. "In preaching one of the things that I hate with a passion is to be boring and so I will go out of my way to try to figure out how to say this in a manner which is understood and interesting."

As stated above, importance was the second most identified factor contributing to the level of effort, but what makes something important? The ministers in this study expressed importance criteria 27 times during the interviews. The most cited criteria for being important was that something follow the mission or goal of a church. Mission as defined here is not "mission statement" but rather calling and purpose of the church as based on the Bible and Christian church history. In fact, three ministers said they ignored their written "mission statement" while fewer than half quoted their "mission statement" even though they all acknowledged having one. After church mission, personal calling was the second most mentioned importance criteria. Personal calling, like church mission above, is rooted in what the ministers believe God has called them to do, which is greatly influenced by their understanding of what the Bible has called all people to do. Minister G summed up these thoughts with the following words:

I think God has given us the mission statements, the great commission. I think that sets the priority. Plus the two great commandments to love the Lord your God with all your heart, soul, mind, and strength and to love your neighbor as yourself. Those three things guide everything I do plus my calling, which fits right into those three things. 


\section{What Factors Influence Ministers to Determine That They Have "Enough" Information to End the Information-seeking Process?}

To explore when ministers determine they have enough information, they were asked, "How did you decide that you had 'enough' information?" and "Why did you stop looking for information?" The answers were often utilitarian. When a minister felt he could accomplish a task, he stopped looking for information.

The stopping behavior of ministers in this study followed one of the following processes.

1. Ministers considered the "diminishing returns" of looking for more information (Zach, "When is "Enough" Enough?" 31). They were comfortable with the current amount of information so they decided to move on. This category can be split into two based on the clarity of the goal.

1. A minister was searching for a specific piece of information and found it. For instance, minister A mentioned troubleshooting a computer problem. When he resolved the problem, he was completely comfortable with the situation and moved on.

2. The type and amount of information needed was very nebulous in the minister's mind, but at some point, the advantages of continuing the information search did not seem to outweigh the advantages of stopping.

2. Ministers were not comfortable with the information they found, but external time constraints forced them to use the information and move on. Minister I read commentaries on a specific Bible passage to prepare for a sermon, but the conclusions of 
the commentaries he read conflicted. At some point, reading more commentaries was not worth the time, so he made do with the information he had.

3. Ministers were not comfortable with their current information, they had enough time to look for more, but doing so generated no more information that was useful. In this case, the ministers were unable to find the information they wanted. Minister D specifically mentioned this as his experience from the past when he worked in a small town, did not have money to buy more books, and the Internet was not available to him.

4. The minister set predetermined criteria. When the committee met the criteria, the information search was over. Unlike the options above, comfort level meant little and only the fact that the information met requirements was important. This case, mentioned by minister $\mathrm{G}$, was in the context of a formal committee with a predetermined task and predetermined goals.

The stopping behaviors did not change significantly when ministers changed roles from administrator to preacher. In critical incidents I-1 through I-17, ministers used stopping processes 1-4. In I-18 through I-23, they used processes 1-3 but not 4. Some of the ministers mentioned that they expected more of themselves and tolerated less error in the role of preacher. Minister A's quote above about hating boring preaching reflects this difference. Minister G cited the Bible and what it says about teaching. The ideas in his quote below come from the Biblical passages of Luke 12:48 and James 3:1 and they reflect how serious he is when seeking information: I know I will be judged more strictly because of my calling. The Bible is very clear about that. A teacher of God's Word will be judged in a different manner and so because of that I approach this with fear. 


\section{Other Information-seeking Habits}

When asked, "Did you identify the type and amount of information you wanted before you started looking or as you went along?" minister responses varied as it related to the critical incidents they described in the first part of the interview. Ministers A, B, F, and I said they looked for information as they went along in the search process. Minister F summarized their sentiments. "I didn't really know what I was going to find out .... So, I wasn't really looking for a specific type of information." Ministers C and E said they both identified some information ahead of time but intended to identify most of that information as they went along. Ministers G and $\mathrm{H}$ said they created a list of questions they wanted answered ahead of time and went about trying to answer those questions. One of those was in the context of a committee and he replied, "We intentionally composed questions very carefully trying to obtain the right information. So yes, we developed our questions first and then we planned their use." However, when analyzing the rest of the interview, even these two ministers adjusted the type and amount of information they wanted as they went along and would therefore fall into the same group as ministers $\mathrm{C}$ and E.

\section{Discussion}

The nature of the information-seeking process used by Baptist ministers in this study varies depending on the role the ministers are taking. While the research identified the three roles of administrator, preacher, and caregiver, only the first two were prevalent. Ministers most often sought information in order to prepare for sermons, but they also dealt with a variety of administrative tasks such as church building issues and church activities. Ministers used informal and formal sources when they sought information about administrative tasks, but formal sources 
such as books and Internet publications were predominant when ministers prepared to teach. Experience related to the task, potential impact, and the importance of the task influenced the effort exerted by ministers. Ministers stopped looking for information when they had enough to complete a task and when spending more time collecting information was no longer worth the effort.

Zach's study found that arts administrators mentioned the informal information channel of personal contacts more often than any other information source ("When is "Enough" Enough?” 29). I based this study in large part on Zach's, but in this study ministers mentioned formal information channels such as books and the Internet more than personal contacts. On the other hand, when I considered role, this study did indeed support Zach's findings. Ministers in the administrative role, which is the only one Zach looked at, used personal contacts most often.

While there has been research about the information-seeking habits of ministers, no one has published a study explaining why ministers stop looking for information. Regardless of role, the ministers in this study usually stopped looking for information for the same general reasons as the arts administrators in Zach's study. "The decision was made when the administrator felt satisfied with the input he had or the decision was forced by external time constraints" (Zach, "When is "Enough" Enough?” 31). Zach’s model shows that people make decisions based on comfort with the information, time left to continue searching for information, whether the current information is "good enough," and the determination of whether more input would improve comfort. One exception to Zach's model appears to be stopping process three, which ends with an unfilled information need. While Zach's models do not depict the possibility of stopping the information search without moving to the next step, she acknowledges this as a possibility when 
she says that they may continue "until they decided to defer completing the task or making the decision" ("When is "Enough" Enough?" 32).

The ministers in this study mentioned sermon information sources 31 times. Of those, only three were informal information channels with two of those being prayer as a source of information. Phillips and Wicks emphasized the different sources used by ministers based on their role. The information collected for this study strongly supports Phillips' findings. Phillips found that ministers used formal channels of information when preparing for sermons, whereas they used both formal and informal channels when accomplishing administrative tasks (126). In addition, the use of prayer as an information source by ministers in this study agrees with Roland's finding that the "leading of the Holy Spirit" is a contributing factor to the actions carried out by ministers (“Clergy Sense-Making” 11).

Ministers often see their primary public role as that of preacher, and they seemed surprised by the question emphasis on administration, in the first part of the protocol, as opposed to preaching. None of the ministers commented that the role of administrator seemed foreign to them, but they did comment that it was more difficult to think of administrator related examples. Minister J said he delegated most administration to other church staff. That was possible for him because his church was the largest in the sample, so that allowed for a greater degree of specialization.

One surprise was that ministers in this study rarely mentioned the role of caregiver even though counseling those in trouble, comforting those in need, and presiding over formal ceremonies are some of the more public ministerial tasks. Only two ministers mentioned caregiving, and only one of those said they searched for information for such situations. That 
minister said he spent more time looking for information in the role of counselor than he did in the role of administrator. Other than the one minister, the lack of comment on counseling may be because the protocol emphasized administration, and the ministers see their primary role as preacher. In addition, ministers may be in the habit of never discussing or even acknowledging counseling in order to safeguard privacy and protect them from litigation.

The life of a Baptist minister can be very hectic between the sermons, ceremonies, counseling, committee meetings, and other responsibilities. The congregation size and staffing greatly affect the responsibilities and demands on a minister. This study considered the information-seeking habits of ministers in one denomination. This exploratory study is not generalizable to all information seekers or all ministers. Therefore, future studies should consider ministers and priests from the Roman Catholic Church, Orthodox churches, and other Protestant denominations. Concepts of worship, sacrament, and education vary widely among these groups, and information-seeking habits may also.

This study and Zach's study focused on the administrative role, but as was shown above, ministers also have an important role as preachers, and their information-seeking habits changed based upon their role. The ministers gave little emphasis to the caregiving role; therefore, a careful study of that role could greatly enhance understanding of minister information-seeking. Researchers studying the information-seeking process in other contexts should also consider whether role influences the seeking behavior of their subjects.

\section{Conclusions}

Baptist ministers varied their information-seeking process based upon the roles they played, primarily the roles of administrator and preacher. When ministers searched for 
information as administrators, they preferred informal sources of information but often used formal sources as well. When searching as preachers, they almost exclusively used formal sources. Experience related to the task, potential impact, and the importance of the task influenced the effort exerted by ministers. When they had enough information to complete a task, and when collecting more information was not worth the effort, ministers stopped looking for information. 


\section{Works Cited}

Allen, Jean Short. "Information-Seeking Patterns and Resource Use by Baptist Leaders in Three Central American Countries..” Diss. U. of North Carolina at Chapel Hill, 1987. Print.

Barna Group. "New Statistics on Church Attendance and Avoidance." The Barna Group 3 Mar. 2008. Web. 30 Dec. 2009.

Blizzard, Samuel W. The Protestant Parish Minister: A Behavioral Science Interpretation. Ed. Harriet B. Blizzard. Storrs: Society for the Scientific Study of Religion, 1985. Print. Society for the Scientific Study of Religion Monograph Ser. 5.

Dervin, Brenda, and Patricia Dewdney. "Neutral Questioning: A New Approach to the Reference Interview.” Research Quarterly 25.4 (1986): 506-513. Print.

Kuhlthau, Carol. Seeking Meaning: A Process Approach to Library and Information Services. Norwood: Ablex Publishing Corp., 1993. Print.

Michels, David H. "Dipping into a Shallow Pool or Beginning a Deeper Conversation: A Case Study of a Minister's Engagement with the Internet for Preaching.” Journal of Religious \& Theological Information 8.3 (2009): 164. Web. 14 June 2010.

Phillips, Robert L. “The Relationship Between Work Roles and Information Seeking Behaviors Among Selected Protestant Ministers in Tarrant County, Texas.” Diss. U. of North Texas, 1992. Print.

Porcella, Brewster. "The Information Gathering Habits of the Protestant Ministers of Cedar Rapids, Iowa.” Diss. U. of Illinois at Urbana-Champaign, 1973. Print.

Roland, Daniel R. "Clergy Sense-Making Behavior and the Sermon Preparation Task.” The 2008 Proceedings of the ASSR-SW. Ed. Jon K. Loessin. Dallas: Association for the Scientific 
Study of Religion-Southwest, 2008. 23-30. Print.

Roland, Daniel R. "Interpreting Scripture in Contemporary Times: A Study of a Clergy Member's Sense-Making Behavior in Preparing the Sunday Sermon.” Diss. Emporia St. U., 2007. Print.

Sarbin, Theodore, and Vernon Allen. "Role Theory." Handbook of social psychology. Ed. Gardner Lindsey \& Elliot Aronson. Reading, Mass.: Addison-Wesley, 1968. 488-567. Print.

Smith, Kevin L., and Vicki L. Smith. "The Impact of the Internet on Parish Ministry - A Survey and Annotated List of Web Resources." Journal of Religious \& Theological Information 4.1 (2001): 9. Print. 29 Dec. 2009.

Tanner, Thomas Michael. “The Pastor as Information Professional: An Exploratory Study of How the Ministers of One Midwestern Community Gather and Disseminate Information.” Diss. U. of Illinois at Urbana-Champaign, 1992. Print.

Wicks, Donald A. "The Information-Seeking Behavior of Pastoral Clergy: A Study of the Interaction of Their Work Worlds and Work Roles." Library and Information Science Research 21.2 (1999): 205-226. Print. 8 June 2007.

Yin, Robert K. Case Study Research: Design and Methods. 2nd ed. Thousand Oaks: Sage Publications, 1994. Print.

Zach, Lisl. "Using a Multiple-case Studies Design to Investigate the Information-Seeking Behavior of Arts Administrators." Library Trends 55.1 (2006): 4-21. Web. 8 June 2007. ---. "When Is "Enough" Enough? Modeling the Information-Seeking and Stopping Behavior of Senior Arts Administrators." Journal of the American Society for Information Science 
and Technology 56.1 (2005): 23-35. Print. 


\section{Apendix A: Interview Protocol}

The purpose of this interview is to investigate how you collected the information you needed for a recent nonroutine task such as initiating a new service, program, or event. When you answer these questions, I would like you to focus on the administrative side of the task. I will also ask you several questions about how you go about looking for information in general.

1. Please describe a recent task you have completed that required you to go out and look for information that you didn't already have.

2. What information did you want to have? [wait for response, then follow up] How did you identify the information you wanted?

3. Where did you look for the information you wanted? [wait for response, then prompt as necessary-identify as many as possible]

a. Didn't look — had the information already

b. Asked someone from another church

c. Asked someone on the staff assigned to the project

d. Asked an information services professional or used a library

e. Hired consultants or research firms

f. Used the Internet or other online sources

g. Used information sources (conversations with colleagues or friends, casual reading, radio listening, television viewing, etc.)

h. Asked God to reveal the answer

i. Used some other source [describe] 
4. If you used information that you already had, do you know where or when you got that information? [wait for response, then prompt as necessary-identify as many as possible]

a. Had enough general knowledge and/or previous experience

b. Heard it from someone in a work-related situation

c. Read it in a work-related publication

d. Heard it from someone in a social situation

e. Came across it in casual reading/radio listening, etc.

f. Other [describe]

5. Why did you select the sources(s) you used for getting the information you wanted? [wait for response, then prompt as necessary-identify as many as possible]

a. Confidence in the source

b. Familiarity with the source

c. Proximity of the source

d. Information was in an easy-to-use format

e. Other [describe]

6. If you got your information from a specific individual, why did you go to that person for information?

7. In collecting information, did you identify the type and amount of the information you wanted before you started looking or as you went along?

8. How did you determine the type and amount of information you actually needed? 
a. Before starting?

b. As you went along?

9. How did you decide that you had "enough" information?

a. Why did you stop looking for more information?

b. Approximately how long did you spend looking for information?

c. Was this typical? Appropriate? What made it different from other experiences?

10. Were you satisfied with the type and amount of information you had when you stopped looking? Why or why not?

11. Did you have to go back and look for more information after you had stopped? Why?

12. How confident did you feel about the information you collected?

13. On what did you base your confidence in the information you got?

14. If you were doing the task over, what would you do differently (if anything) in terms of the way you looked for information?

— Begin general questions. -

15. In general, do you prefer to look at everything that you can find on a subject or do you look for specific information and stop when you have found that?

16. If you look only for the specific information you want to perform a task, how do you determine the type and amount of information you need?

17. Do you feel as if you collect more information than you use? If so, how do you decide what information you actually need? 
18. Does the type and amount of information you feel you need vary depending on your experience with specific types of tasks? Can you give me some examples?

19. Are there other factors that influence the level of effort you spend looking for information? What are they? [wait for response, then prompt as necessaryidentify as many as possible]

20. [Follow up if not specifically addressed in answer to No. 19.]

a. Does the importance of the question/task influence the level of effort you spend?

b. How do you measure/define task importance?

c. Do you use your mission statement to measure/define task importance?

21. What are the most common types of tasks for which you look for information?

22. What are the most common problems you encounter in terms of looking for the information you want to do your job? [wait for response, then prompt as necessary_identify as many as possible]
a. Too much to choose from
b. Not enough on the specific question I have
c. Can't get it quickly enough
d. Don't trust it
e. Other [describe]

23. Do you or your staff use any online sources when collecting information? If so, what are they? If you didn't use any, why not? 
24. Do you think that technology in general has made looking for information easier or harder? Why?

25. Is there anything else you think I should know about the way you look for information and how you decide when you have enough? 
Table I. Critical Incidents and the Minister's Role

\begin{tabular}{|c|c|c|c|}
\hline Incident & Minister & Role & Critical Incident Description \\
\hline $\mathrm{I}-1$ & A & Administrator & Purchasing a new piece of furniture \\
\hline $1-2$ & B & Administrator & Developing a home discipleship program \\
\hline $1-3$ & C & Administrator & Hiring a new part-time children's minister \\
\hline $\mathrm{I}-4$ & D & Administrator & Planning a holiday event \\
\hline $1-5$ & $\mathrm{E}$ & Administrator & Organizing a summer mission project \\
\hline I-6 & $\mathrm{F}$ & Administrator & Implementing a contemporary second service \\
\hline $1-7$ & G & Administrator & $\begin{array}{l}\text { Working with a committee to evaluate the relationship between church } \\
\text { ministries }\end{array}$ \\
\hline I-8 & $\mathrm{H}$ & Administrator & Planning to switch from one church service to two \\
\hline I-9 & 1 & Administrator & Hiring a new music minister \\
\hline $\mathrm{I}-10$ & $\mathrm{~J}$ & Administrator & Planning a missions event \\
\hline $\mathrm{I}-11$ & A & Administrator & Planning a youth event \\
\hline $\mathrm{I}-12$ & B & Administrator & Implementing background checks for teachers of children \\
\hline $\mathrm{I}-13$ & B & Administrator & Writing a new procedure for helping the local needy \\
\hline $\mathrm{I}-14$ & D & Administrator & Supervising a building project and ordering furniture \\
\hline $\mathrm{I}-15$ & D & Administrator & Evaluating whether to maintain a preschool in the church building \\
\hline $\mathrm{I}-16$ & G & Administrator & Organizing home Bible study groups \\
\hline $\mathrm{I}-17$ & G & Administrator & Using a strategy committee to look into church location issues \\
\hline $\mathrm{I}-18$ & $\mathrm{D}$ & Preacher & Investigating moral issues in our culture with intent to use it in a sermon \\
\hline
\end{tabular}




\begin{tabular}{|llll|}
\hline I-19 & E & Preacher & Preparing a controversial sermon series \\
\hline I-20 & H & Preacher & Organizing a sermon with video and graphics support \\
\hline I-21 & I & Preacher & Finding graphics for sermon PowerPoint slides \\
\hline I-22 & I & Preacher & Searching for sermon illustrations \\
\hline I-23 & J & Preacher & Updating his sermons from 20 years ago for today's audience \\
\hline
\end{tabular}

